Can J Ophthalmol. Author manuscript; available in PMC 2014 March 09.

Published in final edited form as:

Can J Ophthalmol. 2013 April ; 48(2): 88-92. doi:10.1016/j.jcjo.2012.09.012.

\title{
Analysis of reasons for noncompliance with laser treatment in patients of diabetic retinopathy
}

\author{
Wen Hua, MD*, Sijia Cao, MD, MSc ${ }^{\dagger}$, Jing Cui, $\mathrm{MD}^{\dagger}$, David Maberley, $\mathrm{MD}^{\dagger}$, and Joanne \\ Matsubara, $\mathbf{P h D}^{\dagger}$ \\ "Department of Ophthalmology, Beijing Chaoyang Hospital, Capital Medical University, Beijing, \\ China \\ †Department of Ophthalmology and Visual Sciences, University of British Columbia, Vancouver, \\ B.C
}

\section{Abstract}

Objective-To identify the underlying reasons for noncompliance among Chinese patients undergoing laser photocoagulation treatment for diabetic retinopathy (DR).

Design-Prospective cohort study.

Participants-A total of 262 patients with DR with indications for panretinal photocoagulation and focal laser treatment were recruited.

Methods-Those who did not complete the prescribed laser treatment were categorized into 2 types of defaulters: Type 1 defaulters were those who did not initiate laser treatment as scheduled; type 2 defaulters were those who did not complete the entire laser sessions, including terminating midterm or defaulting prompt supplement of laser treatment. A standardized questionnaire was given to the 2 types of defaulters to collect information about the reasons for noncompliance. Data were analyzed and subjected to $\chi^{2}$ test or Fisher exact statistical tests.

Results-The noncompliance rate was $45.5 \%$, which is significantly greater than some developed countries. Unawareness of the necessity for treatment and unawareness of the importance to complete treatment were 2 main reasons leading to noncompliance, representing $28.8 \%$ and $36.0 \%$, respectively. Unawareness of the necessity for treatment and fear of laser treatment were more important for type 1 defaulters ( 29 vs 6 and 11 vs 0, respectively), whereas unawareness of completeness of laser treatment was overweighed in type 2 defaulters ( 27 vs 13 patients; all $P<0.01$ ). These results were likely related to the lack of knowledge about the potential consequences of DR, the underlying principle of laser treatment, and panretinal photocoagulation procedures.

Conclusions-Developing appropriate education programs targeting specific reasons will help to improve the compliance in patients with DR.

Correspondence to Joanne Matsubara, Ph.D., Department of Ophthalmology and Visual Sciences, University of British Columbia, Eye Care Centre, 2550 Willow Street, Vancouver BC V5Z3N9; jms@ mail.ubc.ca.

Disclosure

The authors have no proprietary or commercial interest in any materials discussed in this article. 
Diabetic retinopathy (DR) is the leading cause of visual acuity reduction in developed countries, ${ }^{1-3}$ as well as in developing countries. ${ }^{4,5}$ With economic development and life improvement, the diabetic population is estimated to be 92.4 million in adults in China, ${ }^{6}$ and at least $20 \%$ may have complications such as DR. ${ }^{7,8} \mathrm{DR}$ is a microvascular complication that develops in more than $75 \%$ of patients with a 20 -year duration of type II diabetes and in all patients with type I diabetes. ${ }^{2}$ Annual fundus screening and timely intervention by laser therapy in patients with diabetes is the standard of care to prevent visual impairment and blindness from DR. ${ }^{9-11}$ The bulk of the evidence shows that prompt panretinal photocoagulation (PRP) and focal (direct or grid) laser treatment reduced the risk for severe visual loss compared with deferral of treatment over the long term. ${ }^{12-17}$

Several studies in the United States have shown that many patients with diabetes fail to seek or receive dilated eye examination and timely treatment according to guidelines, and the average compliance rate may vary from approximately $30 \%$ to $60 \% .{ }^{18-20} \mathrm{~A}$ variety of factors contributed to the high noncompliance rate, such as transport, absence of a decision maker, fear of laser treatment, socioeconomic barriers, health system barriers, educational barriers, and cultural barriers. ${ }^{21-23}$ According to our clinical experience, the same issues occurred in Chinese patients with diabetes, but the underlying factors were unclear. Moreover, many patients defaulted from the laser treatment in progress, although many reports showed that the supplementary laser photocoagulation and the subsequent follow-up were as important as the initial laser sessions. ${ }^{24-26}$

The literature shows the value of educational programs in improving patient adherence to guidelines when the programs targeted specific reasons behind the noncompliance. ${ }^{27-30}$ To identify the noncompliance with laser treatment in Chinese patients with DR and the underlying reasons, we recruited 262 patients with diabetes with indications for laser treatment and conducted a survey on the reasons for default among defaulting patients. The clarification of the reasons might further enable us to design specific education program and content to improve the compliance in Chinese patients with diabetes.

\section{Methods}

The patients were recruited at the Department of Ophthalmology, Beijing Chaoyang Hospital in the period from April 2010 to December 2011. This study was conducted according to the tenets of the Declaration of Helsinki and was approved by the Institutional Review Board at Beijing Chaoyang Hospital, affiliate of Capital Medical University.

We recruited 262 patients into this study. All patients underwent a full ophthalmologic examination (best corrected visual acuity, slit-lamp examination, noncontact tonometry, fundus biomicroscopy, and indirect fundus examination) and anatomic examination (color photography, fluorescein angiography, optical coherence tomography). These patients had either severe nonproliferative or early proliferative DR and met the indications for starting laser treatment. The laser photocoagulation treatment consisted of full-scatter PRP treatment performed during 3 sessions (at weeks 1, 2, and 3) according to the Early Treatment Diabetic Retinopathy Study (ETDRS) guidelines. Four to six hundred 200- $\mu \mathrm{m}$ spots were performed per PRP session at the discretion of the same treating investigator. Supplement of 
laser treatment was promptly given when necessary. Macular focal laser photocoagulation guided by fluorescein angiography was also performed in cases with clinically significant macular edema at the first laser treatment session (week 1) and was repeated after 3 months in cases of persistent macular edema.

Among 262 recruited patients, 119 patients either failed to initiate the laser treatment or were not able to complete the entire laser treatment and were hereby termed as "defaulters." We categorized the defaulters into two types: Type 1 defaulters were the patients who did not initiate the laser photocoagulation as scheduled; type 2 defaulters were those who initiated the laser treatment but did not receive the entire routine laser treatment as scheduled, including quitting during the laser therapy and defaulting prompt supplement of laser treatment. Both types of defaulting patients were given the same questionnaire to collect information about the compliance of laser therapy, including age, sex, occupation, residential region, convenience of transport, economic status of family, support from family members or friends, awareness of the necessity for laser treatment, awareness of the importance to complete laser treatment, experience from friend, recommendation by friend, and fear of decrease in vision or loss of visual field, or both, by photocoagulation. The data were analyzed using a $\chi^{2}$ test or a Fisher exact test by GraphPad Prism 5 software (GraphPad, La Jolla, Calif.).

\section{Results}

In this study, we registered 262 patients with DR who had indications for immediate laser photocoagulation treatment consisting of full-scatter PRP treatment and macular focal (direct or grid) laser photocoagulation. Only 143 (54.6\%) patients completed the entire laser treatment, and the remaining 119 patients were defaulters, of which 73 (27.9\%) were type 1 defaulters, who failed to start the laser treatment, and 46 (17.6\%) were type 2 defaulters, who were unable to complete the entire treatment. We successfully retrieved 65 of the 73 type 1 defaulters (retrieval rate $83.0 \%$ ) for participation in a questionnaire. The retrieval rates among male and female patients were $51.2 \%$ and $49.7 \%$, respectively. The main causes in order for default in type 1 defaulters were unawareness of the necessity for treatment (29 patients, 44.6\%), unawareness of the importance to complete laser treatment (13 patients, $20.0 \%$ ), fear of laser treatment (11 patients, 16.9\%), fear of decrease in vision or loss of visual field, or both, by photocoagulation (5 patients, 7.7\%), inconvenience of transport (6 patients, $9.2 \%$ ), and economic status of family (1 patient, $1.5 \%$; Table 1 ). The retrieval did not vary by residential region and sex (data not shown).

We successfully retrieved all 46 type 2 defaulters for participation in the questionnaire (retrieval rate 100\%). The retrieval rates among male and female patients were $48.9 \%$ and $52.1 \%$, respectively. The most important reasons for defaulting in type 2 defaulters were unawareness of the importance to complete laser treatment (27 patients, 58.7\%) and fear of decrease in vision or loss of visual field, or both (8 patients, $17.4 \%)$. The other causes for defaulting included unawareness of the necessity for laser treatment (6 patients, 13.4\%), inconvenience of transport ( 2 patients, $4.3 \%$ ), support from family members or friend ( 2 patients, $4.3 \%$ ), and economic status of family (1 patient, $2.2 \%$; Table 1 ). The retrieval did not vary by region or sex (data not shown). 
The factors that contribute to different types of defaulting from the laser treatment were analyzed using the $\chi^{2}$ test (Fig. 1). The composition of reasons between type 1 and type 2 defaulters were different. Of the reasons for defaulting, unawareness of the necessity for laser treatment, unawareness of the importance to complete laser treatment, and fear of laser treatment were statistically different between type 1 and type 2 defaulters $(P<0.01$, Fisher exact test).

\section{Discussion}

Laser photocoagulation is the standard of care in the management of DR, in addition to the systematic control of glycemic level and blood pressure. PRP reduces the vascular load on the posterior pole and allows the remaining tissue to receive an adequate blood supply by destroying the hypoxic tissues. ${ }^{31,32}$ Focal (direct or grid) laser coagulation benefits patients with diabetic macular edema probably by the closure of leaking microaneurysms. The largescale studies demonstrated that laser photocoagulation reduced risk for severe visual loss by $50 \%$ or more. ${ }^{12,13,15,33}$ In terms of medical expenses, early detection and timely intervention were more cost-effective than managing severe complications of DR such as vitreous hemorrhage and neovascular glaucoma. ${ }^{34-36}$ Therefore, the laser therapy is routinely proposed to patients with severe nonproliferative and proliferative DR and/or diabetic macular edema in clinic. However, our data showed that among 262 patients with DR with laser therapy indications, $72.1 \%$ of patients initiated the therapy and only $54.6 \%$ completed the entire therapy sessions. The noncompliance rate was $45.4 \%$. Compared with the $85 \%$ Will et al. ${ }^{20}$ reported in 1994, the compliance in our study was far from satisfactory, which largely compromised the effectiveness of laser photocoagulation as a means of disease prevention. Of note in Will's report was that the blindness prevention education program probably contributed to the high compliance, which provides us with a good indication that appropriate education programs may help to improve the compliance of Chinese patients with DR with laser treatment.

To further understand the high noncompliance rate, we retrieved defaulting patients to selfidentify the reasons behind their choice. Unawareness of the necessity for treatment and unawareness of the importance to complete laser treatment were 2 main reasons leading to default, representing $28.8 \%$ and $36.0 \%$, respectively. More interestingly, the weight of these 2 reasons was significantly different in 2 types of defaulters (Table 1). Unawareness of the necessity for treatment was more important for type 1 defaulters characterized by failure to initiate laser therapy, whereas unawareness of the importance to complete laser treatment was overweighed in type 2 defaulters, who withdrew halfway from the ongoing laser sessions (Fig. 1). Unawareness of the necessity for treatment reflected the lack of knowledge about the potential consequences of DR in defaulters, and a previous report showed that this knowledge was critically important for patients to make decisions to pursue the treatment. ${ }^{27}$ Without sufficient motivation, patients were more likely to be less certain about initiating laser treatment. Education focusing on the facts of DR before the proposed laser treatment may help patients make an informed decision. Compared with type 1 defaulters, many type 2 defaulters assumed that the laser therapy was complete after the first round(s) of laser sessions. This misconception likely resulted from the incomplete knowledge of the principle of laser treatment and PRP procedures. The same reason might also lead to the fear of laser 
treatment in type 1 defaulter, whereas with experience of treatment, type 2 defaulters may have overcome this psychological barrier. Therefore, different strategies in terms of education content should be taken in different types of defaulting patients: For type 1 defaulters, knowledge of natural history of DR and evidence-based benefits of laser treatment should be clarified before the treatment proposal. This information will help patients to establish the confidence in laser therapy and improve the attendance rate, whereas for type 2 defaulters, the emphasis should be given on the procedures of treatment, including the number of sessions required and the potential necessity for supplementary laser session in case of disease progression. ${ }^{37}$

Our study demonstrated that fear of decrease in vision or loss of visual field (or both), inconvenience of transport, economic status of family, and support from family members or friends were 4 minor factors contributing equally to type 1 and type 2 default (Table 1).

Although clinicians usually do not have concerns about its safety, the laser coagulation is not free of adverse effects, which includes decreased visual acuity and visual field. ${ }^{38,39}$ The careful balancing of reward and risk, and effective communication with patients before treatment proposal should help to overcome this barrier. The patient population in this study did not encounter much restraint in terms of finance, transport, and support, and it may be associated with our hospital location. The patient population in this study was mostly from the urban Beijing area, and this population was characterized by having high economic status, good insurance coverage, and easy access to modern health care facilities. ${ }^{40}$

To the best of our knowledge, this is the first report of noncompliance with laser photocoagulation treatment in Chinese patients with DR that includes the underlying reasons as identified by patients. Our study revealed a big gap of knowledge among patients with DR concerning laser treatment, which can be potentially filled with appropriate education. The education content should not be limited in why laser treatment is necessary, but also include how laser treatment is performed. In terms of timing, we suggest that the education should start before the treatment proposal is made, given the fact that type 1 defaulters (73/262 patients) were greater than type 2 defaulters ( $46 / 262$ patients).

Poor compliance with laser treatment is a major impediment to prevent blindness in patients with DR. With the information about reasons for noncompliance, ophthalmologists and other health care providers should make more effort to develop appropriate educational programs and eliminate treatment barriers.

\section{Acknowledgments}

We thank Xiaolong Zhang for help in statistic analysis.

\section{References}

1. Klein R, Klein BE, Moss SE, Davis MD, DeMets DL. The Wisconsin epidemiologic study of diabetic retinopathy. IV. Diabetic macular edema. Ophthalmology. 1984; 91:1464-74. [PubMed: 6521986]

2. Klein R, Klein BE, Moss SE, Davis MD, DeMets DL. The Wisconsin epidemiologic study of diabetic retinopathy. III. Prevalence and risk of diabetic retinopathy when age at diagnosis is 30 or more years. Ophthalmology. 1984; 102:527-32. 
3. Moss SE, Klein R, Klein BE. The 14-year incidence of visual loss in a diabetic population. Ophthalmology. 1998; 105:998-1003. [PubMed: 9627648]

4. Preti RC, Motta AA, de Maia OO Jr, et al. Relationship between diabetic retinopathy severity and the timespan between the endocrinopathy diagnosis and the first ophthalmic examination. Arq Bras Oftalmol. 2010; 73:240-3. [PubMed: 20730280]

5. Khandekar R, Mohammed AJ. Visual disabilities among diabetics in Oman. Saudi Med J. 2005; 26:836-41. [PubMed: 15951879]

6. Yang W, Lu J, Weng J, et al. Prevalence of diabetes among men and women in China. N Engl J Med. 2010; 362:1090-101. [PubMed: 20335585]

7. Wang N, Xu X, Zou H, Zhu J, Wang W, Ho PC. The status of diabetic retinopathy and diabetic macular edema in patients with type 2 diabetes: A survey from Beixinjing District of Shanghai city in China. Ophthalmologica. 2008; 222:32-6. [PubMed: 18097178]

8. Xie XW, Xu L, Wang YX, Jonas JB. Prevalence and associated factors of diabetic retinopathy. The Beijing Eye Study 2006. Graefes Arch Clin Exp Ophthalmol. 2008; 246:1519-26. [PubMed: 18604548]

9. Fong DS, Aiello L, Gardner TW, et al. Retinopathy in diabetes. Diabetes Care. 2004; 27:S84-7. [PubMed: 14693935]

10. American College of Physicians, American Diabetes Association, and American Academy of Ophthalmology. Screening guidelines for diabetic retinopathy. Ann Intern Med. 1992; 116:683-85. [PubMed: 1546870]

11. Peng J, Zou H, Wang W, et al. Implementation and first-year screening results of an ocular telehealth system for diabetic retinopathy in China. BMC Health Serv Res. 2011; 11:250. [PubMed: 21970365]

12. The Diabetic Retinopathy Study Research Group. Photocoagulation treatment of proliferative diabetic retinopathy. Clinical application of Diabetic Retinopathy Study (DRS) findings, DRS Report Number 8. Ophthalmology. 1981; 88(7):583-600. [PubMed: 7196564]

13. Early Treatment Diabetic Retinopathy Study Research Group. Early photocoagulation for diabetic retinopathy. ETDRS report number 9. Ophthalmology. 1991; 98(5 Suppl):766-85. [PubMed: 2062512]

14. Flynn HW Jr, Chew EY, Simons BD, Barton FB, Remaley NA, Ferris FL 3rd. Pars plana vitrectomy in the Early Treatment Diabetic Retinopathy Study. ETDRS report number 17. The Early Treatment Diabetic Retinopathy Study Research Group. Ophthalmology. 1992; 99:1351-7. [PubMed: 1407968]

15. Early Treatment Diabetic Retinopathy Study research group. Photocoagulation for diabetic macular edema. Early Treatment Diabetic Retinopathy Study report number 1. Arch Ophthalmol. 1985; 103:1796-806. [PubMed: 2866759]

16. Browning DJ, Glassman AR, Aiello LP, et al. Diabetic Retinopathy Clinical Research Network. Relationship between optical coherence tomography-measured central retinal thickness and visual acuity in diabetic macular edema. Ophthalmology. 2007; 114:525-36. [PubMed: 17123615]

17. Olk RJ. Modified grid argon (blue-green) laser photocoagulation for diffuse diabetic macular edema. Ophthalmology. 1986; 93:938-50. [PubMed: 3763140]

18. Lee PP, Feldman ZW, Ostermann J, Brown DS, Sloan FA. Longitudinal rates of annual eye examinations of persons with diabetes and chronic eye diseases. Ophthalmology. 2003; 110:19529. [PubMed: 14522771]

19. Paz SH, Varma R, Klein R, Wu J, Azen SP. Los Angeles Latino Eye Study Group. Noncompliance with vision care guidelines in Latinos with type 2 diabetes mellitus: the Los Angeles Latino Eye Study. Ophthalmology. 2006; 113:1372-7. [PubMed: 16769120]

20. Will JC, German RR, Schuman E, Michael S, Kurth DM, Deeb L. Patient adherence to guidelines for diabetes eye care: results from the diabetic eye disease follow-up study. Am J Public Health. 1994; 84:1669-71. [PubMed: 7943494]

21. Khandekar R, Al Lawati J, Barakat N. A retrieval system for patients with avoidable blindness due to diabetic retinopathy who do not present for ophthalmic assessment in Oman. Middle East Afr J Ophthalmol. 2011; 18:93-7. [PubMed: 21731317] 
22. Mukamel DB, Bresnick GH, Wang Q, Dickey CF. Barriers to compliance with screening guidelines for diabetic retinopathy. Ophthalmic Epidemiol. 1999; 6:61-72. [PubMed: 10384685]

23. Cuadros J, Bresnick G. EyePACS: an adaptable telemedicine system for diabetic retinopathy screening. J Diabetes Sci Technol. 2009; 3:509-16. [PubMed: 20144289]

24. Vine AK. The efficacy of additional argon laser photocoagulation for persistent, severe proliferative diabetic retinopathy. Ophthalmology. 1985; 92:1532-7. [PubMed: 4080327]

25. Kaufman SC, Ferris FL 3rd, Seigel DG, Davis MD, DeMets DL. Factors associated with visual outcome after photocoagulation for diabetic retinopathy. Diabetic Retinopathy Study Report \#13. Invest Ophthalmol Vis Sci. 1989; 30:23-8. [PubMed: 2912911]

26. Reddy VM, Zamora RL, Olk RJ. Quantitation of retinal ablation in proliferative diabetic retinopathy. Am J Ophthalmol. 1995; 119:60-766.

27. Reno PL, Arfken CL, Heins JM, Fisher EB Jr. Factors that influence the decision to receive treatment for proliferative diabetic retinopathy. Diabetes Educ. 1997; 23:653-5. [PubMed: 9416028]

28. Zhang X, Norris SL, Saadine J, et al. Effectiveness of interventions to promote screening for diabetic retinopathy. Am J Prev Med. 2007; 33:318-35. [PubMed: 17888859]

29. Walker EA, Schechter CB, Caban A, Basch CE. Telephone intervention to promote diabetic retinopathy screening among the urban poor. Am J Prev Med. 2008; 34:185-91. [PubMed: 18312805]

30. Halbert RJ, Leung KM, Nichol JM, Legorreta AP. Effect of multiple patient reminders in improving diabetic retinopathy screening. A randomized trial. Diabetes Care. 1999; 22:752-5. [PubMed: 10332676]

31. Wolbarsht ML, Landers MB 3rd. The rationale of photocoagulation therapy for proliferative diabetic retinopathy: a review and a model. Ophthalmic Surg. 1980; 11:235-45. [PubMed: 6155650]

32. Mohamed Q, Gillies MC, Wong TY. Management of diabetic retinopathy: a systematic review. JAMA. 2007; 298:902-16. [PubMed: 17712074]

33. Early Treatment Diabetic Retinopathy Study design and baseline patient characteristics. ETDRS report number 7. Ophthalmology. 1991; 98:741-56. [PubMed: 2062510]

34. Javitt JC, Aiello LP. Cost-effectiveness of detecting and treating diabetic retinopathy. Ann Intern Med. 1996; 124:164-9. [PubMed: 8554212]

35. Javitt JC, Aiello LP, Chiang Y, Ferris FL 3rd, Canner JK, Green-field S. Preventive eye care in people with diabetes is cost-saving to the federal government. Implications for health-care reform. Diabetes Care. 1994; 17:909-17. [PubMed: 7956643]

36. Dasbach EJ, Fryback DG, Newcomb PA, Klein R, Klein BE. Cost-effectiveness of strategies for detecting diabetic retinopathy. Med Care. 1991; 29:20-39. [PubMed: 1898753]

37. The Early Treatment Diabetic Retinopathy Study Research Group. Techniques for scatter and local photocoagulation treatment of diabetic retinopathy: Early Treatment Diabetic Retinopathy Study Report no. 3. Int Ophthalmol Clin. 1987; 27:254-64. [PubMed: 3692707]

38. Fong DS, Girach A, Boney A. Visual side effects of successful scatter laser photocoagulation surgery for proliferative diabetic retinopathy: a literature review. Retina. 2007; 27:816-24. [PubMed: 17891003]

39. Early Treatment Diabetic Retinopathy Study Research Group. Focal photocoagulation treatment of diabetic macular edema. Relationship of treatment effect to fluorescein angiographic and other retinal characteristics at baseline: ETDRS report no. 19. Arch Ophthalmol. 1995; 113:1144-155. [PubMed: 7661748]

40. Liu M, Zhang Q, Lu M, Kwon CS, Quan H. Rural and urban disparity in health services utilization in China. Med Care. 2007; 45:767-74. [PubMed: 17667311] 


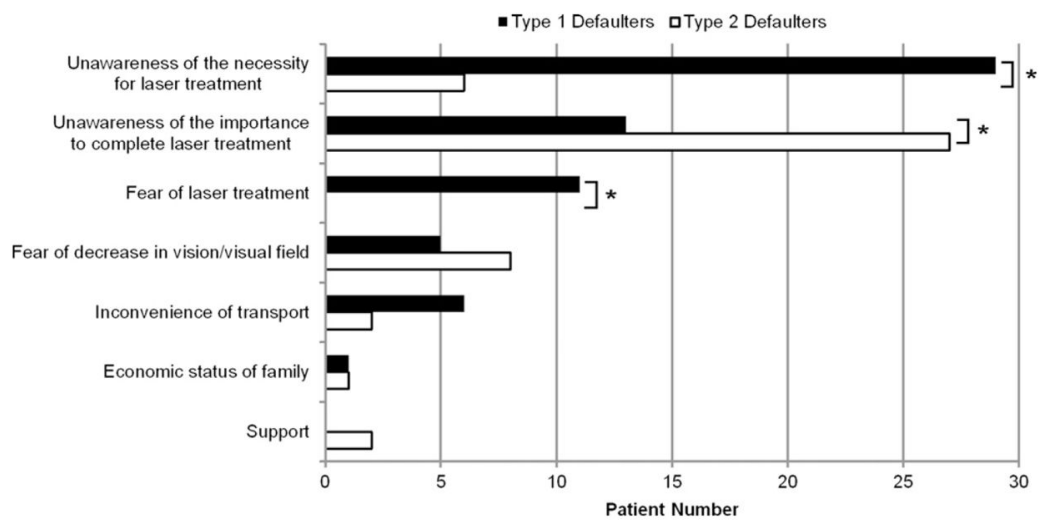

Fig. 1.

Comparison of default reasons between type 1 and type 2 defaulters. Of the reasons, unawareness of the necessity for laser treatment, unawareness of the importance to complete laser treatment, and fear of laser treatment were statistically different between type 1 and type 2 defaulters $(* P<0.01$, Fisher exact test). 


\section{Table 1}

Common reasons for default of prescribed laser treatment for diabetic retinopathy

\begin{tabular}{|lccr|}
\hline Reason & Type 1 defaulters & Type 2 defaulters & $\boldsymbol{P}$ \\
\hline Unawareness of the necessity for laser treatment & $29(45 \%)$ & $6(13 \%)$ & 0.0004 \\
Unawareness of the importance to complete laser treatment & $13(20 \%)$ & $27(59 \%)$ & $<0.0001$ \\
Fear of laser treatment & $11(17 \%)$ & 0 & 0.0025 \\
Fear of decrease in vision/visual field & $5(8 \%)$ & $8(17 \%)$ & 0.2416 \\
Inconvenience of transport & $6(9 \%)$ & $2(4 \%)$ & 0.2890 \\
Economic status of family & $1(1.5 \%)$ & $1(2 \%)$ & 1.0000 \\
Support & 0 & $2(4 \%)$ & 0.2009 \\
Total & 65 & 46 & \\
\hline
\end{tabular}

